PPPL-2274

UC20-F

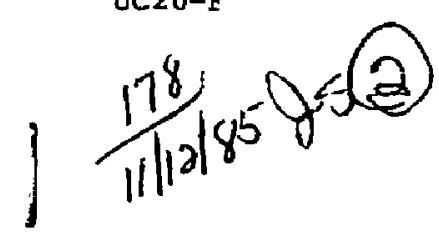

$$
I-23790
$$

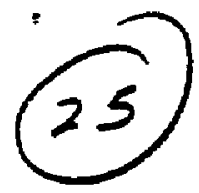

MEASUREMENT OF POPULATION INVERSTONS 7ND GAIN IN CARBON FIBER PIASMAS

PPPL--2274

DE86 002532

By

H. Milchberg, C.H. Skinner, S, Suckewer, D. Voorhees

OCTOBER 1985

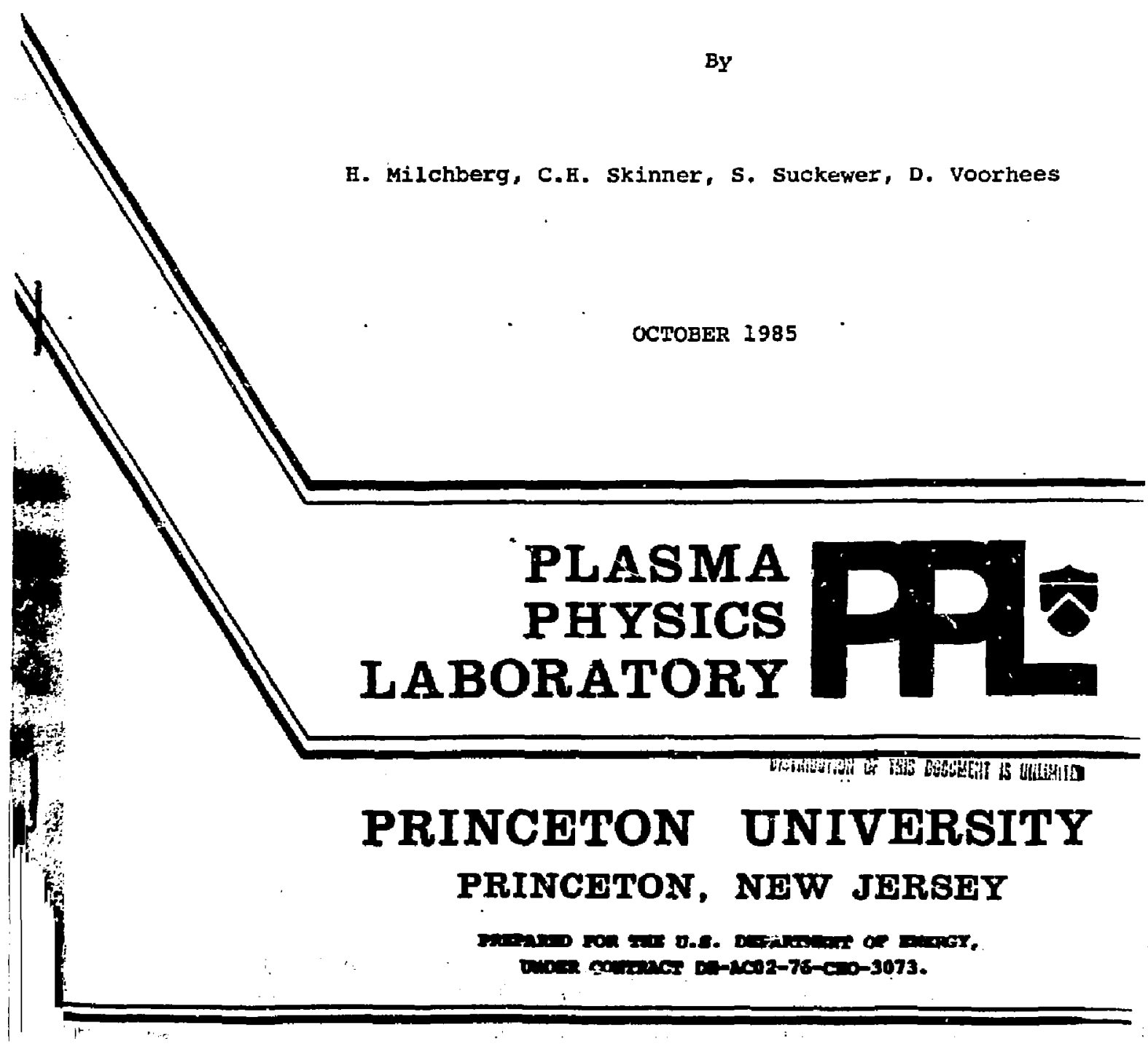


MEASUREMENT OF POPULATION INVERSIONS AND

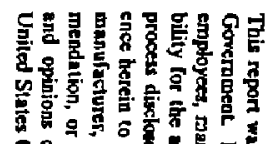

GAIN IN CARBON FIBER FLASMAS

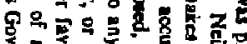

H. Milchberg*, C.H. Skinner, S. Suckewer, D. Voorhees

Plasma Physics Laboratory

Princeton Universit;

Princeton, New Jersey 08544

ABSTRACT

A $\mathrm{CO}_{2}$ laser $(\sim 0.5 \mathrm{~kJ}$ energy, 70 nsee pulse width) was focussed onto the end of an axially oriented, thick (35-350 $\mu$ ) carbon fiber with or without a magnetic field present along the laser-fiber axis. We present evidence for axial-to-transverse enhancement of the CVI $182 \mathrm{~A}$ (n $=3 \rightarrow 2$ ) transition, which is correlated with the appearance of a population inversion between levels $n=3$ and 2 . For the $B=0 \mathrm{kG}$, zero field case, the maximum gain-length product of $k \ell=3\left(k * 6 \mathrm{~cm}^{-1}\right)$ was measured for a carbon fiber coated with a thin layer of aluminum (for additional radiation cooling). The resulis are interpreted in terms of fast recombination due mostly to thermal conduction from the plasma to the cold fiber core.

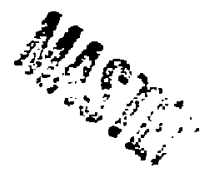

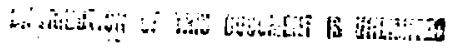
$\therefore \hat{b}$

*Present adaress: AT \& T Bell Laboratories, Murray Hill, N.J. 07974 
Recently, several groups have presented experimental evidence for significant gain in the soft $\mathrm{X}$-ray region. An axial enhancement of $\mathrm{E}=100$ of stinulated emission over spontaneous emission, and a corresponding gain-length product of 6.5 has been achieved in a recombining plasina produced by the interaction of a $\mathrm{CO}_{2}$ laser with a carbon disc in the presence of a $\mathrm{B}=90 \mathrm{kG}$ magnetic field. 1 A different approach, electron excitation of neon-like selenium, has produced gains of $k \mathrm{l}=5-7$ at the Novette waser facility at Livermure. 2 A separate experiment, ${ }^{3}$ also based on a seleniun-coated plastic foil, reported a gain-length product $k l \cdot 4$ on the CVI $182 \mathrm{~A}$ line from fast recombination due to rapid cooling by selenium radiation. A gain-lentth of 1 $-2 \mathrm{~cm}^{-1}$ has also been repnrted 4 in Al XI at $105.6 \mathrm{~A}$.

In previous experiments with carbon fibers, Pert et al. 5 adopted an approach in which a thin ( 6 山 diameter) carbon fiber was transversely illuminated ty a line-focussed Nd-glass laser. Gain-lengths $k £ 5$ were reported on the CVI $182 \mathrm{~A}$ transition. The results were interpreted in terns of a detailed theoretical modei based on hydrodynamic expansion of a cylindrical plasma with attendant adiabatic cooling indueing fast recombination and gain. ${ }^{6}$

In our work, based on radiation cooling of a plesma confined in a magnetic field, investigacion of different targets and the resultant plasma geometries 7,8 indicated that end-on illumination of a carbon fiber could produce a long, thin plasma suitable for high gain.

The experimental setup has been presentej previously. 9 Briefly, a $5 x$ $10^{12} \mathrm{~W} \mathrm{Cm}^{-2}, 50-80 \mathrm{nsec}$ FWH $\mathrm{CO}_{2}$ laser pulse was focussed onto the end of a carbon fiber supported by spider webs in an evacuated chamber inside a $90 \mathrm{kG}$ solenoidal magnet (see Fig. 1). The laser focal spot was a 200 $\mu \quad x 00$ u ellipse. The $\mathrm{CO}_{2}$ laser beam, fiber, and magnetic field were aligned along a common axis. The fiber targets were 4-5 mm long and ranged in dianeter from 
35-350 $\mu$. Fibers in the range 70-350 w were fabricated from number $2 \mathrm{H}$ pencil leads, or by placing together two on more 35 u diameter fibers. The narrow fibers were cut from graphite strands. Some fibers were coated with a thin layer of aluminum for additional radiation cooling. xuv grazing incidence and air wavelength monochonators observed the plasma emissions from the entire fiber in both transverse and axial directions. The XuV instruments were absolute intensity calibrated in situ by the branching ratio technique using a specially designed portable vacuum spark. ${ }^{10}$ The vacuum spark was also used to measure the relative sensitivity of the axial and transverse xuv instruments. Laser-produced plasmas from calibration fibers oriented perpendicular to both axial and transverse instruments were used to confirm the relative sensitivity and extend the absolute intensity calibration to shorter wavelengtis $(25-80 A), \theta$

Figure 1 shows framing camera images in the visible wavelength range of the laser-axial fiber interaction, with and without the magnetic field present. 10 In both cases the plasma extended along the length of the fiber. For $B=90 \mathrm{kG}$, the plasma was well contained and elongated, whila for $B=0$ the plasma extended over a larger volume and much of the support strands was heated. Since the lower charge states of carbon have strong radiative transitiors in the viaible wavelength range, care must be taken in interpreting the framing images in terms of the CVI geometry. In particular, the plasma generated by the support strands is only heated so low charge states by the fringe of the Iaser bean, but nevertheless appears with high intensity in the $\mathrm{B}=0 \mathrm{kG}$ image lat $\mathrm{B}=0 \mathrm{~kg}$ the plasma expanding from the fiber appears to increase the interaction of the laser bear fringe with the support stzands). The transverse width of the plasme image is also weighted to the lower charge states and is much larger than the region containing 
CVI. However, the framing images do give a qualitative picture of the plasma and show a long, thin plasma geometry suitable for generating high gain. The laser interaction alang the fiber is not, at present, well understood and may be facilitated by a hollow electron density profile ${ }^{11,12}$ produced at the fiber tip or may be promoted by hot electrons generated in the laser-plasma interaction. 1 :

Rapid recombination of totally stripped carbon, $c^{6+}$, can produce population inversions between levels $n=3$ and 2 , and gain on the CVI 182A ( $n$ $=3+2$ transition). In the experiment, gain was measured by two independent methods: (a) from the ratio of axial to transverse CVI $182 \mathrm{~A}$ emission and (b) from the absolute level of the population difference between levels $n=3$ and 2. In the first method, the ratio of axial to transverse signals was normalized by the relative sensitivity of the axial and transverse instruments as deteruined from the spark and "perpenaicular' fiber ca:ibration. The enhancement, $E_{\text {, }}$ is defined as the ratio of stimulated plus spontaneous axial emission to spontaneous emission in the transverse directior. In the absence of gain, E should be unity. To avoid the possibility that the Eiber obscured part of the plasma from the view of the transverse instrument, we conservatively take only a measured $E>2$ as evidence for gain. In fact, the measured value of $\mathrm{E}$ was never less than 0.8 which gave w confidence that both axial and transverse instruments viewed essentially the same plisma.

Figure 2 shows the results from the fiber shot having the highest enhancement. The time history of the CVI $182 \mathrm{~A}(3 \rightarrow 2$ transition) line

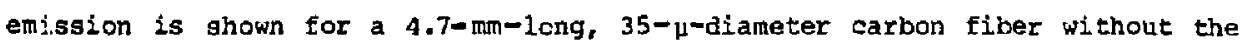
magnetic fiela. The fiber was coated with $\sim 8000$ f of aluminum. The enhancement was measured to be $E * 6$ and, in the small signal approximation, can be related to the gain-length product, $k \ell$ by $E=[\exp (k \ell)-1] / k \ell$. This 
yielas $k \&=3$ corresponding to $k * 6 \mathrm{~cm}^{-1}$. At tile peak of the CrI $33 A$ emission, the population inversion ratio $N_{3} / g_{3}: N_{2} / g_{2}$ was measured to be 4.3:1. Here $\mathrm{N}$ is the population and $\mathrm{g}$ the statigtical weight. While direct measurements of the CVI geometry in the fiber plasma were not available, a spatial scan of a similar plasma generated from a thin $(300 \mu)$ carbon blade was performed on a shot to shot basis (the blade target was usable for many laser shots). For $B=0 \mathrm{kG}$, the width of the CVI $182 \mathrm{~A}$ emission was measured ${ }^{7}$ to be less than $200 \mu$. If, on this basis, the fiber plasma diameter is taken to be $150 \mu$, the absolute intensity calibration yields a CVI $\mathrm{n}=3$ population of $2 \times 10^{15} \mathrm{~cm}^{-3}$. For this population with a $182 \mathrm{~A}$ Doppler-broadened line at $10 \mathrm{ev}$, the calculated gain is $\mathrm{k} \times 8.2 \mathrm{~cm}^{-1}$ and is consistent with the gain measured from the $182 \mathrm{~A}$ intensity ratio. The effect of the aluminum coating is positive, but no systematic investigation of these coacings was undertaken. The region near $10 \mathrm{eV}$ and below is propitious for three-body recombination, and temperatures in this region have been measured in our recombining carbon plasmas. 10 The brightness temperature of the axial emission calculated from the measured intensity of $4.2 \times 10^{4}$ watts $\mathrm{sr}^{-1}$, (area $1.8 \times 10^{-4} \mathrm{~cm}^{2}$ ) is 2.2 kev, much higher than the temperature of the recombining plasma.

Figure 3 shows the results from 16 fibers, 8 with a 90 kG magnetic field present. The $B=90 \mathrm{kG}$ data show no population inversion and no significant axial entancement. The $\mathrm{B}=0 \mathrm{kG}$ data, however, show bo'h population inversions and enhancements. The correlation of observed population inversions with enhancement is strong evidence for stimulated emission. There was no obvious correlation of gain with fiber diameter, as slight variations in laser focal spot alignment caused some scattur in the data and impeded a more systematic study. 
Rapid conling after the laser pulse is required in order to generste fast recombination and high gain. Three possitile mechanisms for this are considered: hydrodynamic expansion, heat conduction to the cold fiber core, and radiation cooling.

In the carbon fiber plasma calculations of Pert et al, $, 5,6$ the effectiveness of expansion cooling relies on the high initial density $\left[n_{e} \leqslant\right.$ $10^{21} \mathrm{~cm}^{-3}$ ) and small initial diameter $(\leqslant 6 \mu)$ of the plasma. However, as the size of the fiber increases, it is less likely that it will be fully ionized for a given laser pulse. In principle, the incomplete ionization of the fiber core would provide a low temperature heat sink which could cool the surrounding plasma much more rapidly than adiabatic expansion. This has been slown in a simple calculation in which the rates of rooling due to expansion and thermal conduction are separately calcuiated and then compared. ${ }^{10}$ The rate of conduction cooling was calculated from the time-dependent, classical radial heat flow equation, while expansion was taken to occur with the radial component of the ion thermal velocity, with the temperature controlled by the adiabatic equation of state. In this calculation, it is assumed that at the end of the laser pulse, an axisymmetric annular plasma of auter radius $r_{P}$ and temperature $T_{P}$ is situated around a cold fiber core of radius $r_{f}$ and temperature $T=0$. Beyond $r=r_{p^{\prime}}$ the plasma densi.ty and temperature drop quickly due to expansion during the laser pulse. This low density, outlying plasma is not important for achieviug high grin, and it is neglected. During the laser pulse, not treated explicitly in the calculation, heat is thermally conducted frot the absorption region to the continuously ablating, cold fibet surface.

Figure 4 shows the ratio of the instantaneous rates of thermal conduction cooling to expansion cooling for a wide range of plasma and fibez 
geometries. Here $v$ denotes the cooling rates, and $\mathrm{n}_{\mathrm{e}}=10^{19} \mathrm{~cm}^{-3}$ and $\mathrm{kT}_{\mathrm{p}}=300$ eV are electron densities and initial temperatures typical for $\mathrm{CO}_{2}$ laserproduced plasmas. In this regime of relatively large fiber diameter, conduction cooling is at least an order of magnitude faster thas axpansion cooling. Conduction cooling is thus expected to reduce the plastia temperature long before expansion reduces the plasma density appreciably. This is a desirable outcome on the basis of the large absolite population density required for lasing action.

Radiation cooling of a pure carbon fiber plisma can be shove to be less effective than conduction cooling. ${ }^{10}$ The presence of impurities such as a) uminum should increase the cooling rate, 9

For $B=90 \mathrm{kG}$, and if little magnetic flux is excluded from the plasma, the classical electron thermal conductivity decreases by a factor of $\sim 20$ for the conditions of Fig. 4. This can remove conduction as a cooling channel. The absence of inversion and enhancement for $B=90 \mathrm{kG}$ in Fig. 3 might also be explained by increased electron collisional coupling between cVI levels $n=2$ and $n=3$ at the higher densities maintained by the field.

In conclusion, correlated population inversions and gains have been demonstrated for carbon fiber plasmas with the largest gain being $\sim 6 \mathrm{~cm}^{-1}$. Thermal conduction to the relatively cold fiber core remaining after the laser pulse is proposed as the dominant cooling mechanism.

Future experinents will investigate, in more detail, the nature of the axial lager-fiber coupling, and the effect of varying the thicknesses of aluminum coatings on the population inversions and gains. 


\section{ACKNOWL EDGMENTS}

The authors would like to acknowledge helpful discussiong with Dr. J.L. Schwob. C. Keane, D. DiCicco, and C. Green are also to be thanked for help in the experiments.

This work was supported, in part, by DOE Basic Energy Sciences Contract No. XC-05-01, Air Proce Office of Scientific Research Contract No. AFosR-840025, and by a National Science and Engineering Research Council of Canada Scholarship. 


\section{REFEREMCES}

1. S. Suckewer, C.H. Skinner, H.M. Mllchberg, C. Keane, and D. Voorheeg, Princeton Plasma physics Laboratory Report No. PPPL-2207, March 1985; Phys. Rev. Iett. (to be puillshed).

2.

D.L. Matthews, P.L. Hagelatein, M.D. Rogen, M.J. Eckart, N.M, Ceglio, A.U. Jazi, H. Medecki, B.J. MacGokan, J.E. Trebes, B.L. Whitten, E.M. Camphell, C.H. Hatcher, A.M. Hawryluk, R.I. Kauffian, L.D. Pleasance, G. Rambach, J.H. Scofield, G. Stone, and T.A. Heaver, Phys. Rev. Lett. 54, $110(1985)$.

3. J.F. Seeley, C.M. Brown, U.Feldman, M. Pichardson, B. Yaakob, and W.E. Behring, Opt. Commun. 54, 289 (1985).

4. G. Jamelot, E. Jaeglè, and A. Carillon, Ann. Phys. Fr. 9, 657 (1984).

5. D. Jacoby, G.J. Pert, L.D. Shorrock, and G.J. Tallents, J. Phys. B 15, 3557 (1982).

F. G.J. Pert, J. Phys. B $9,3301(1976)$.

7. C.H. Skinner, C. Keane, H. Milchberg, S. Suckewer and D. voorhees, in Laser Techniques in the Extreme vitraviolet, ed, 5 , Harris and $T$. Iucatorto, (A.I.P., New York, 1984) P. 372.

8. H. Wilchberg, J.L. Schwob, C.H. Skinner, S. Suckewer, and D. Voorhees, ibid, p. 379 .

9. 5. Suckewer, C. Keane, H. Milchberg, C.H. Skinner, and D. Voarhees, ibid, p. 55 .

10. G. Milchberg, Ph.D. thesis, Princeton University, 1985.

11. L.C. Johnson and T.K. Chu, Phys. Rev. Lett. 32, $517(1974)$.

12. E.A. Crawford and A.I. Hoffman, in Laser Interaction and Related Plasma Phenomena, Vol. 6. ed. H. Hora and G. Miley, (PIenum, N.Y., 1984) PP. 353-367.

13. D.V. Giovanielli, J.F. Kephart, and A.H. Williamg, J. Appl. Phys. 47, $2907(1976)$. 


\section{FIGURE CADTIONS}

Fig. 1

Carbon fiber target coated with a thin layer of aluminum for which the highest gain was observed. Framing images of the $\mathrm{CO}_{2}$ laser-fiber interaction at $B=0,90 \mathrm{kG}$.

Eig. 2 . CVI $182 \mathrm{~A}$ intensitieg for the fiber target in Fig. 1 with an enhancement $E=6$ and a gain of $6 \mathrm{~cm}^{-1}$.

Fig. 3. Enhancement (E) vs population inversion for 16 fiber shats. Open cizcles: $B=0$ KG, no Al coating; solid circles: $B=90 \mathrm{kG}$, no Al coating: open/solid triangles: fibers with $8000 \mathrm{~A}$ aluminum coating $(B=0$ and $B=90 \mathrm{~kg}$, respectively).

Fig. 4. Calculated instantaneous rates of thermal conduction cooling and expansion cooling for various fiber and plasma radii ( $r_{f}$ and $r_{p}$ ) for a temperature of $300 \mathrm{eV}$ and electron density $10^{19} \mathrm{~cm}^{-3}$. 
$\# 85 \times 1410$

CARBON FIBER $4.7 \mathrm{~mm} \times 35 \mu$ Dia. $\sim 8000 \AA$ Af Coating

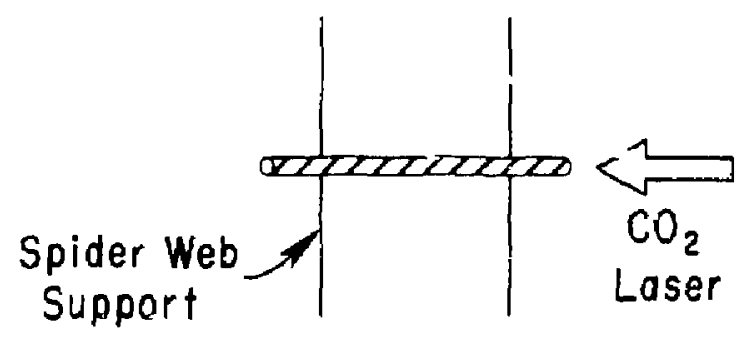

FRAMING IMAGES 200 ns Exposure
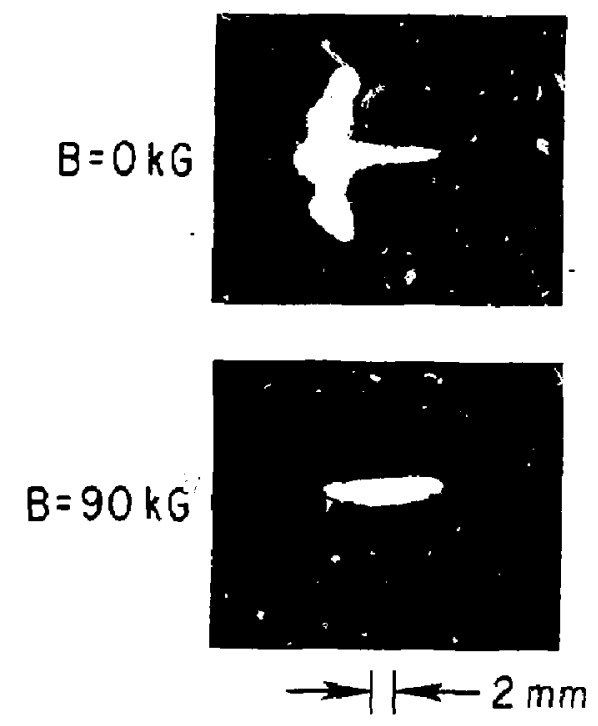

F1gure 1 

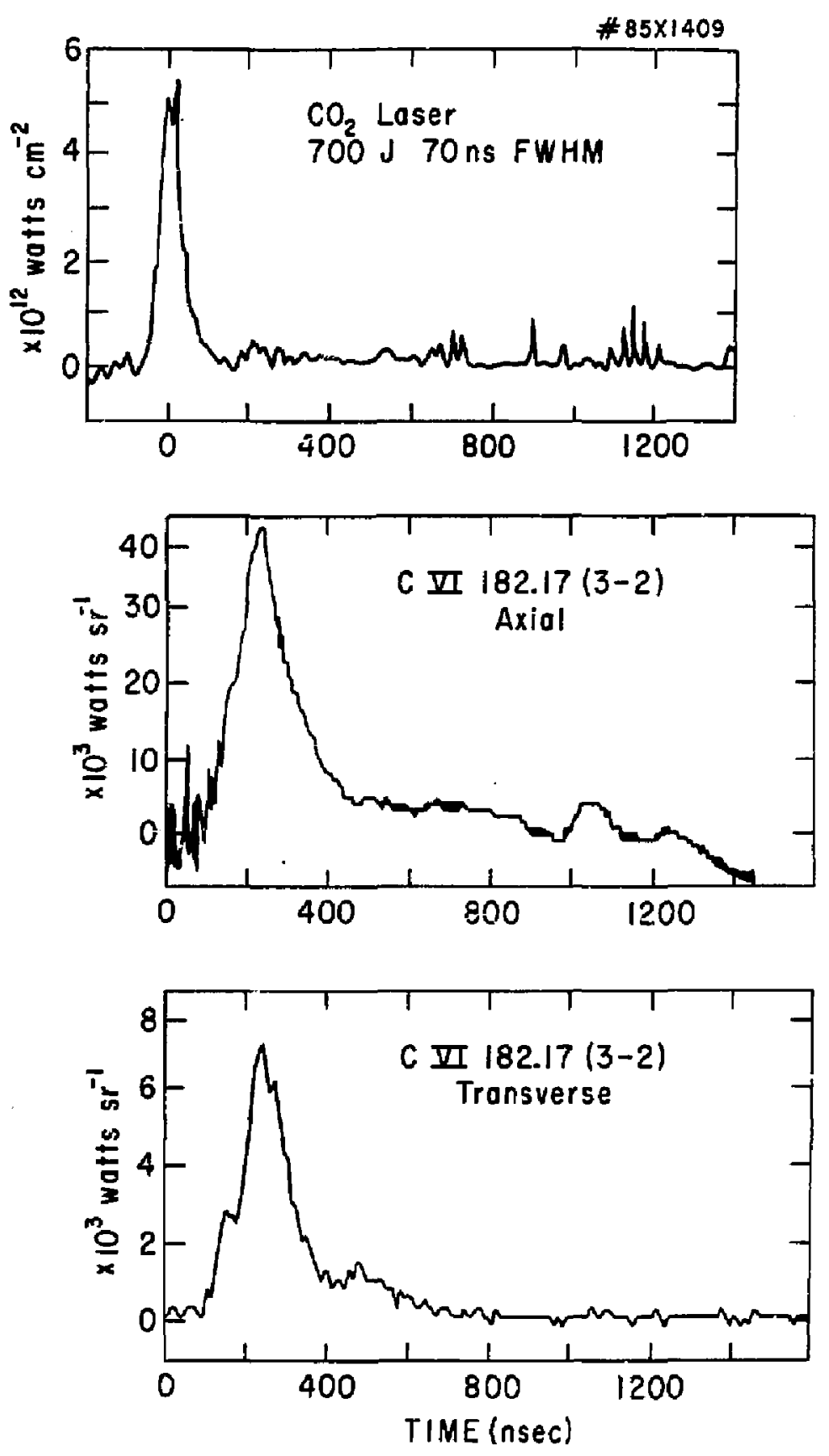

Figure 2 


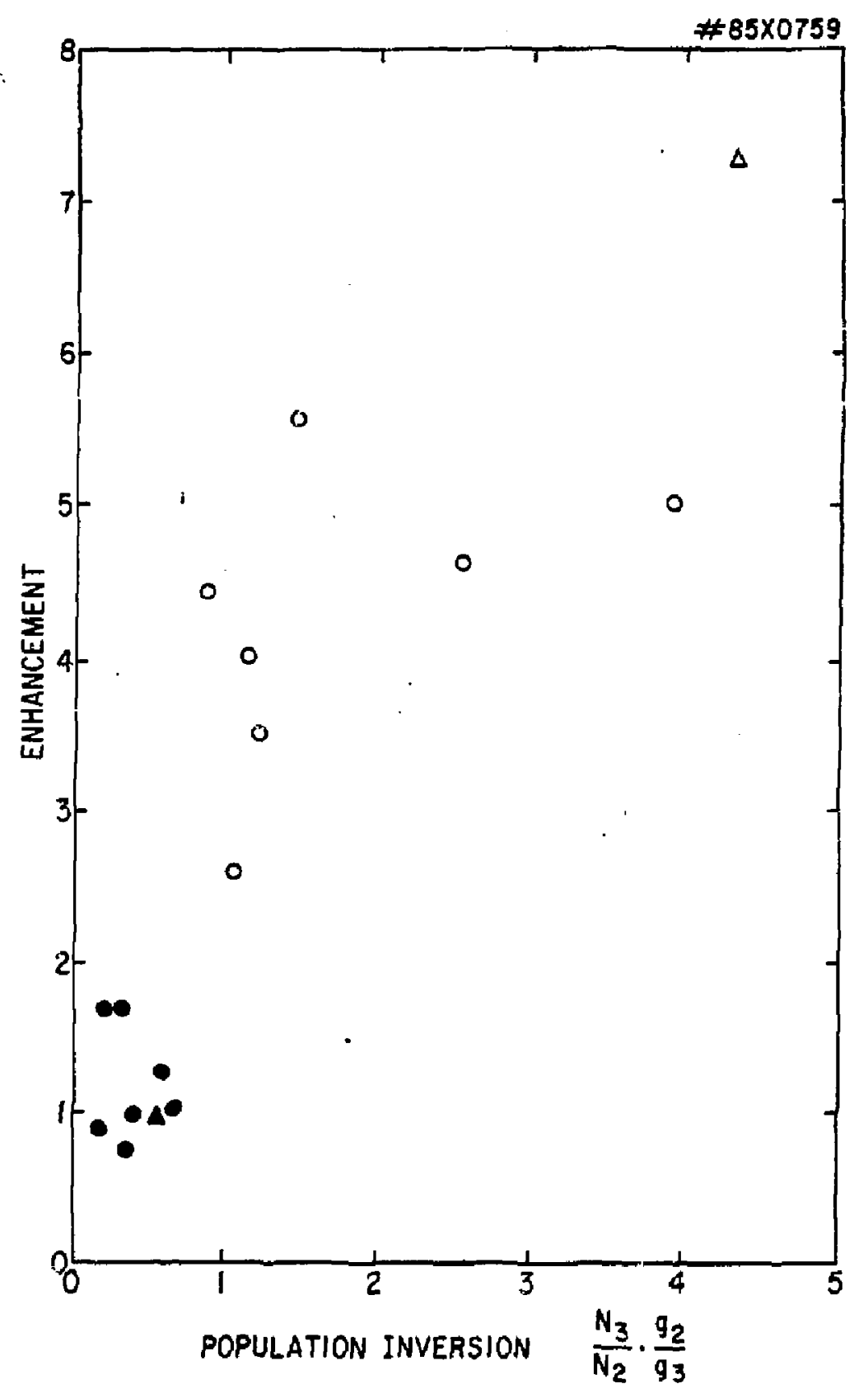

Figure 3 


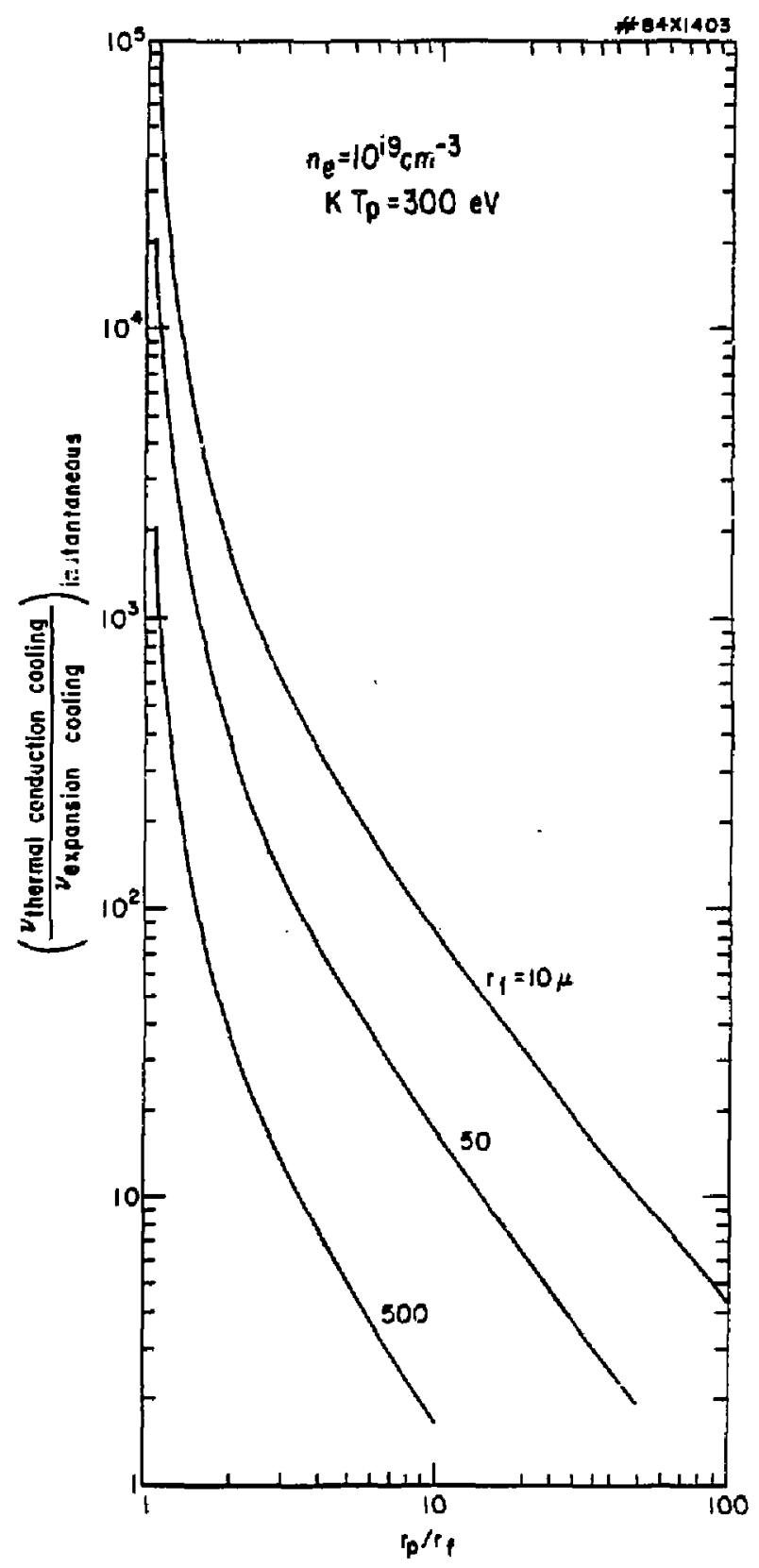

Figure 4 


\section{EXIEAPL DISIRIBUTLON DN ADDRMLAN TO LC-20}

$$
\begin{aligned}
& \text { AETR JULIOEO FY } \\
& \text { BEST AVAILARLE: }
\end{aligned}
$$

Plage Res Lab, Augtra Nat'l univ, ALSTRNA DE. Frark J. PaOloni, Uhiv of wollongong, AustratitA Prof. I.R. Jones, Flinders Univ., eustratsth Prof. M.K. Frennan, thiv Sydney, AusiphI Prof. F, Capr Inst theo Fyss, ALILIA Prof. Exark verheest, Inst theoretlsche, ExGIM Dx. D. Palumbo, Dg XIF Fusion Prog, BeckuM

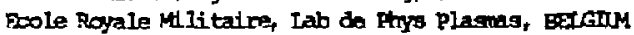
Dr. P.t. Sakanaka, Univ Estadual, ERATIL Dr. C.R. James, Dniv of Alberta, civon Prof. J. Teichmam, Univ of Montreal, CaNpaA Dr. F.M. Skargart, univ of Saskatowar, Capas Etof. S.R Sreenivasen, University of Calgary, CAluna Prof. Nudor W. Johnston, TNRS-Energle CANDA DF. Hames Bamard, Dhiv British Columbia, Canda Dr. M.F. Bachysaki, MFA Technologies, Inc, DANAA Chalje River, Mal Lab, Canada

Thengin Lit, st Inst Prysics, Gma

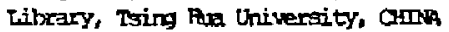
tibrarian, Ingtitute of Ptrysios, cting Inst Plasma Fhys, Acaktila sinica, CImA

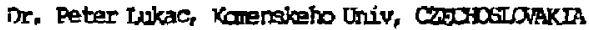
The Lithrarian, Gulhan Laborabocy, ENTAND Prof. Scinatzman, obseratoire de Nice, ERANCE J. Radet, Cost-EA, BFANCE AM Dupas Library, AH Dupas Tibrary, ERANCE Dr. TIm Mral, Acadeny Ribllographic, torg karg

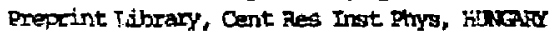
Dx. S.K. Trehan, Panjab Unlversity, IDIA Dr. Indra Mohan Lal Das, Eanaras Finty Univ, INIA DF. I.K. Chavea, South Gujarat Dniv, IDDIA DI. Rox Ohrajlani, viluan univ. INDIA Dr. B. Dasgupta, Saha Inst, InDIA DT. P. Kaw, Fhysical Research Lab, RDIA Dr. Phillip Romall, Istael Inst Tech, JSRAR Prof. S. Opentan, Tel Aviv thiversity, ISFAE Prof. G. Rostagni, Dnily Di Paiovin, Dealy Iirsrarian, Int'1 Gr theo Ptiss, IIHTY Miss Clelia De Palo, Aasoc buRATón-ESEh, IIALY Biblioteca, del ONR ELPATOM, ITHLY

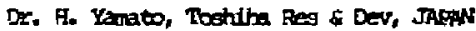
Direc Dept. La. Tokamak Dev. JAERI, JAPASt Prof. Wokryuki Inoue, Univengity of Tukyo, JAPAN

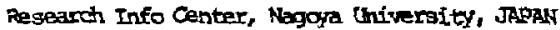
Prof. Kyoji Nishikana, Univ of Hiroshima, JAPAK Prof. Sigen Mori, JAEN, IAPAN ifbrary, Kyoto Undversity, JAFAN Prof. Ictiro Kostakani, Wihor Iniv, IRPAN Prof, Satoghi Itoh, Kyrghu University, JAPAN DI. D.I. Croi, Adv. Ingt Sci \& Tech, KOREA Tech Info Divigion, KAERI, KOREA Pibliotheek, Fon-Inst voor Plasna, NEIFFrisas

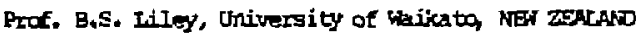
Prof. J.A.C. Cabral, Inst Superioc neen, pokturat. D. Octavian Petrus, ALI CUAA University, ROMANIA Frof. Mo ho Halluerg, University of Natal, 90 AFrica D.. Johan de Vilizees, Plasma thysics, Mucor, SO AFRTCA. Fusion tiv, Itbrary, JDN, SPAN Proc. Pans wilhelnson, chalmen univ Tech, SWEDN De. Lemart Stenflo, thiversity of UMIPA, SMDEN Iibsary, Royal Inst Tech, ShEDDN

Centre de necherdegen, Doole Polyted Fed, SWIIZEREAND Dr. V.T. Tolok, Mharkov Fhys Tech Ins, IISSR Dr. D.D. Ryutor, Sibecian Acad Sci, USSR Dr. G.A. Elisecev, kurciatov Institate, ISST Dr. V.A. Glukhilh, Inst Electro-Physical, USSR Inotibute Gen Fhysico, USSR

Prof. T.J.M Boy, Univ college is tales, wares DT. K. Schindler, Rhr oniversitat, W. GPRMANY Mrclear Res Estab, Julich Lud, W, GERANY Libratan, Mux-tland Institut, w. Gors: Bibliothek, Inst Plasnaforschumg, w. GEPMANK Prof. R.K. Jansv, Inst Phys, YugastaWIA 